\title{
Fuzzy neural networks' application for substation integral state assessment
}

\author{
A. I. Khalyasmaa, S. A. Dmitriev, S. E. Kokin \\ \& S. A. Eroshenko \\ Automated Electrical Systems Department, Ural Federal University \\ named after the first President of Russia B.N. Yeltsin, Russia
}

\begin{abstract}
This paper addresses the problems connected with fuzzy neural networks' application in equipment technical state assessment problems at electrical substations. This paper discusses the main principles of fuzzy neural network formation and its construction algorithm. Also, the case study for the determination of fuzzy neural network synaptic weights for the unit "disconnector" on the basis of technical diagnostic statistical data and tests is presented.

Keywords: fuzzy neural networks, technical state assessment, Enterprise Asset Management Systems, electrical substations, synaptic weights.
\end{abstract}

\section{Introduction}

Nowadays many grid companies in Russia, owning $35 \mathrm{kV}$ and above electric substations, the automated Enterprise Asset Management (EAM) systems to enhance the technical and economic performance of their work are developing. Grid companies are striving to reduce the risks associated with failures and outages, to reduce the costs of maintenance and repair of power equipment and to optimize their investments [1].

The increased interest of grid companies explained as follows. Firstly, most of the substation power equipment in Russia operates much longer than its admissible lifetime. Secondly, the system scheduled preventive maintenance requires significant financial costs and highly labor intensity. This is due to the fact that today the substations are not owned by the state but are private property. 
It characterizes the system scheduled preventive maintenance as technically and economically inefficient for grid companies. Therefore, many companies are trying to move from a system of scheduled preventive maintenance system to the condition monitored maintenance system. Such a transition is possible only if the use of techniques and equipment based on the technical diagnostic methods such as electrical, thermal, optical, acoustic, etc [2].

In Russia, the technical state assessment system of power equipment at the substations within the EAM system include various monitoring methods and special (additional) measuring or testing of equipment does not by regulations. The development of such systems leads to an increase of capital investments, which proportionally depend on the number of substations owned by the grid company. Assessment of reliability of such systems and their accuracy is also a separate task.

At present in Russia there are different technical diagnostics methods, most of them are required and regulated by federal technical standard of Russia for all or almost all kinds of electrical power equipment. Therefore, the statistics data of technical diagnostics is present at each grid company, which allows us to use these data for power equipment technical state assessment and to make predictions about electrical equipment residual life.

According to statistics, only for $20 \%$ of the equipment total number at the substation technical diagnostics is necessary. For the remaining $80 \%$ diagnostics is a formal process. This means that $80 \%$ of the information will be an unused.

In this paper, the authors proposed a mathematical model for power equipment technical state assessment on the basis of technical diagnostics using hybrid neural networks. Power equipment technical state assessment at the $35 \mathrm{kV}$ and above substations is one of the most pressing problems for electricity networks in Russia.

This is due to the fact that most of the substation equipment in excess of the normal period of operation is used, which leads to a deterioration of quality indicators stability of equipment and requires special attention during the operation and application of various methods control of its state [3].

For modeling the system of power equipment technical state assessment various mathematical methods are using. But for the automated power equipment technical state assessment requires the use of such a mathematical method which would provide reliability and accuracy of the results and not would overload the system of redundant data (due to the complexity and multi-criteriality of the task itself).

The use of fuzzy logic is explained by the fact that the power equipment technical state assessment at the $35-500 \mathrm{kV}$ substations can also be considered as an applied problem, the solution of which and linguistic and numerical data are using, such as, for example, "the equipment state" etc. 


\section{Problem solution}

The main idea of hybrid networks methodology is membership functions determination using fuzzy sets, where defuzzification is performed using ANN [4]. This implementation allows us to take advantage of both methods and helps to get rid of input data "scale" and to construct the knowledge database more compactly and efficiently. $35-500 \mathrm{kV}$ substation equipment technical state assessment is carried out using hybrid training algorithm of fuzzy control module, the block diagram of which is presented in Fig. 1.

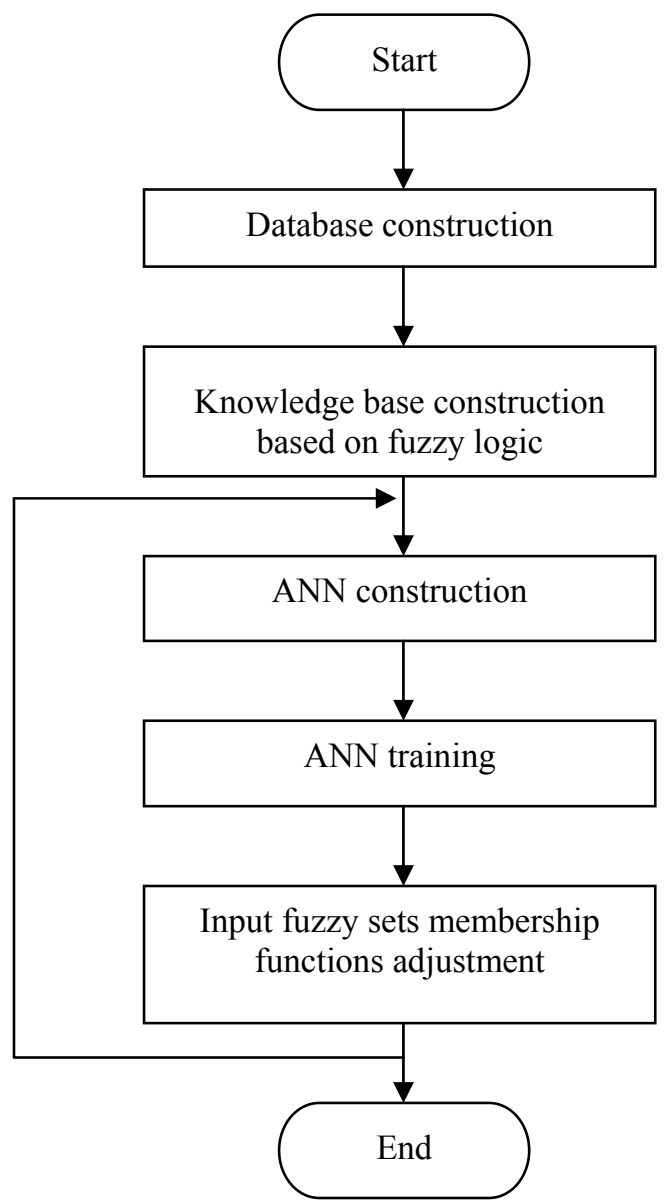

Figure 1: Block-diagram of fuzzy control module hybrid training algorithm. 
Integral assessment of substations requires separate fuzzy control module algorithm for each type of equipment. Technical state assessment is carried out for the following types of equipment:

- 110-500 kVswitchgear;

- $35 \mathrm{kV}$ switchgear;

- $10 \mathrm{kV}$ switchgear;

- power transmission lines;

- power transformers;

- relay protection and emergency automation.

It is notable that switchgear objects are combined of separate equipment units:

- bus sections,

- circuit breakers,

- disconnectors,

- current transformers,

- voltage transformers,

- surge arresters.

Each unit consists of components. For example, the power transformer consists of the following components:

- magnetic system,

- windings,

- transformer oil,

- tap changer,

- high-voltage bushing,

- cooling system,

- transformer tank etc.

Thus, the algorithm of fuzzy control module is used for power equipment technical state assessment in three stages: the stage of power equipment unit's assessment (including their internal components; the stage of combined objects assessment; the stage of the entire substation objects assessment.

This paper discusses the unit "disconnector". "Disconnector" consists of the following units (which are most often used at substations in Russia):

- 6-15 kV disconnector;

- $35-500 \mathrm{kV}$ disconnector.

\section{Case study}

In [3] the formation principle of the power equipment technical state assessment system at the substations and rules base - states equipment classification rules are described. In this paper, attention is given to the database, namely the formation of nomenclature defects and input parameters list for the fuzzy neural network.

One of the main parameters in the construction of any neural network, including a fuzzy neural network is synaptic weights [5]. Therefore, the determination of synaptic weights can be isolated in a separate problem, which will also be discussed later. 
First we need to define a list of tests and diagnostics based on which will form the database (input parameters). The list of methods, formulated on the basis of requirements document and statistical data obtained during the research performed by the authors in the last 5 years is presented in Table 1.

For the formation of a fuzzy neural network for a unit "disconnector" is necessary to determine the synaptic weight for each of the test shown in Table 1.

In many articles for solving such problems the value of synaptic weights based on expert judgment are calculated. But the method of expert judgment is not a reliable method and is entirely dependent on the human factor.

The authors proposed to use Bayesian method to determine the synaptic weights, which allows calculating the probability conformity diagnosed object to different states with appearance of property for each type of test or diagnostic. Using this method the synaptic weights based on the probability appearance at one of four states - diagnoses are determined:

1) features within the normal, there are no defects $\left(D_{1}\right)$;

2) features within the normal, there are defects $\left(D_{2}\right)$;

3) features outside the norm, there are no defects $\left(D_{3}\right)$;

4) features outside the norm, there are defects $\left(D_{4}\right)$.

Taking into account that the features of each type test are independent, the object state is characterized by a complex of independent features, each $K$ of which is a two-bit $K=\left(k_{1}, k_{2}\right)$,

where $k_{1}$-feature $K$ appearance, $k_{2}$ - vice versa.

In this paper we propose a method for determining the appearance probability based on the characteristic membership functions. Appearance probabilities (no appearance) by processing statistical information on failures are determined (Table 1).

Table 1: $\quad$ Probability of a two-bit features appearance for a disconnector.

\begin{tabular}{|c|c|c|c|c|c|c|c|c|}
\hline Test & \multicolumn{2}{|c|}{$D_{1}$} & \multicolumn{2}{|c|}{$D_{2}$} & \multicolumn{2}{|c|}{$D_{3}$} & \multicolumn{2}{|c|}{$D_{4}$} \\
\hline 1. Production year & 0.820 & 0.180 & 0.030 & 0.970 & 0.0213 & 0.979 & 0.050 & 0.950 \\
\hline $\begin{array}{l}\text { 2. Insulation resistance } \\
\text { measurement of multi- } \\
\text { element insulators }\end{array}$ & 0.950 & 0.050 & 0.025 & 0.975 & 0.0019 & 0.998 & 0.180 & 0.820 \\
\hline $\begin{array}{l}\text { 3. Insulation resistance } \\
\text { measurement of single- } \\
\text { element insulators }\end{array}$ & 0.960 & 0.040 & 0.044 & 0.956 & 0.0039 & 0.996 & 0.045 & 0.955 \\
\hline $\begin{array}{l}\text { 4. Insulation test of } \\
\text { secondary circuits and } \\
\text { electromagnet control } \\
\text { winding }\end{array}$ & 0.980 & 0.020 & 0.020 & 0.980 & 0.0087 & 0.991 & 0.030 & 0.970 \\
\hline $\begin{array}{l}\text { 5. Contact system } \\
\text { resistance measurement }\end{array}$ & 0.930 & 0.070 & 0.025 & 0.975 & 0.0029 & 0.997 & 0.055 & 0.945 \\
\hline 6. Operating test & 0.800 & 0.200 & 0.045 & 0.955 & 0.0025 & 0.997 & 0.090 & 0.910 \\
\hline $\begin{array}{l}\text { 7. Thermal imaging } \\
\text { control of contact joint }\end{array}$ & 0.910 & 0.090 & 0.020 & 0.980 & 0.0023 & 0.998 & 0.065 & 0.935 \\
\hline$P\left(D_{i}\right)$ & & & & & 0 . & & & \\
\hline
\end{tabular}


The probability of each state for various combinations features by the Bayes formula is determined [6]:

$$
P\left(D_{i} / K\right)=\frac{P\left(D_{i}\right) P\left(K / D_{i}\right)}{\sum_{s=1}^{n} P\left(D_{s}\right) P\left(K / D_{s}\right)},
$$

where $K$ - set of a two-bit features $\left\{k_{1}, k_{2}, k_{3}, \ldots, k_{v}\right\}, n$ - number of diagnoses state, $P\left(D_{i}\right)$ - pre-diagnosis probability $D_{i} ; P\left(K / D_{i}\right)$ - probability of feature appearance in the diagnosis $D_{i}$, calculated as follows:

$$
P\left(K / D_{i}\right)=P\left(k_{1} / D_{i}\right) P\left(k_{2} / D_{i}\right) \ldots P\left(k_{v} / D_{i}\right),
$$

This analysis provides a quantitative characteristic combination of diagnosable state for features belonging to a different state. In turn, based on such characteristics by priority weighting coefficient of the investigated factors are determined. The resulting values presented in Table 1.

Result analysis of probability of feature appearance is shown in Fig. 2. As a result, ranging of probability of feature appearance in emergency state $\left(D_{4}\right)$ presented in Table 2 .

Application of the Bayesian method in problems of determining the fuzzy neural network synaptic weights makes it possible to get a more accurate result than using expert judgment methods. This in turn makes it possible to obtain a more correct fuzzy neural network structure.

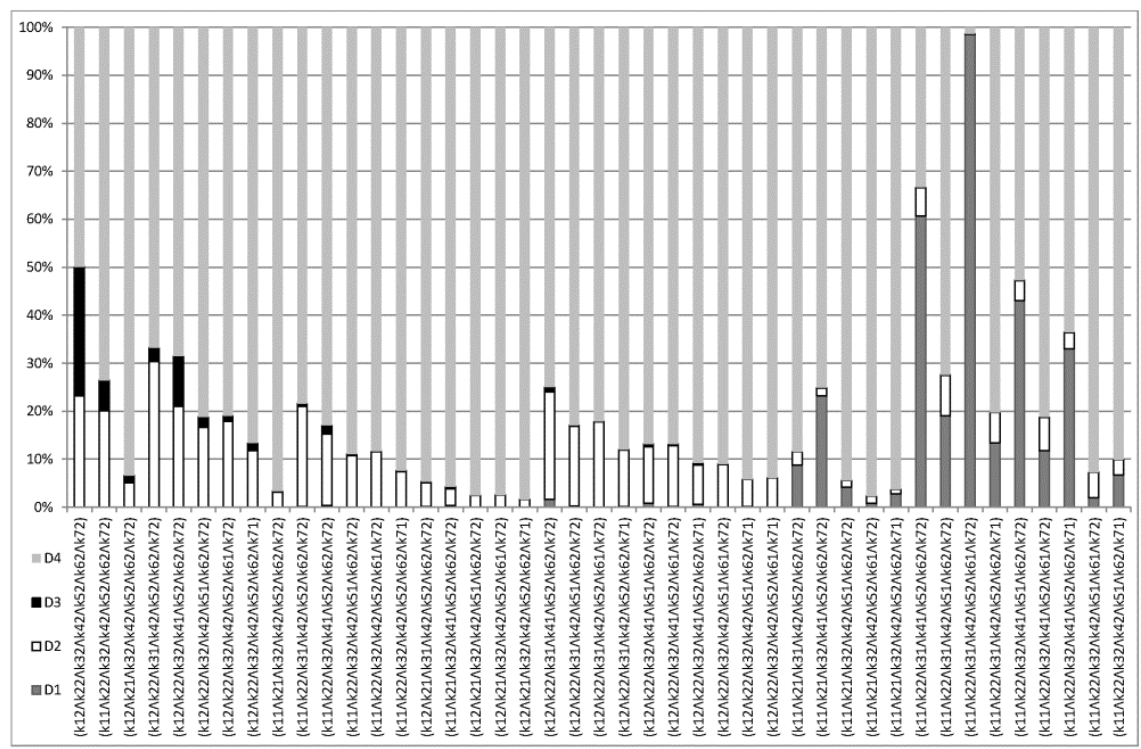

Figure 2: The distribution diagram of probability of a two-bit features appearance (no appearance). 
Table 2: $\quad$ Synaptic weights for the unit "disconnector".

\begin{tabular}{|l|l|c|}
\hline & \multicolumn{1}{|c|}{ Test } & Weight \\
\hline 1 & Production year & 2 \\
\hline 2 & Insulation resistance measurement of multi-element insulators & 4 \\
\hline 3 & Insulation resistance measurement of single-element insulators & 2 \\
\hline 4 & $\begin{array}{l}\text { Insulation test of secondary circuits and } \\
\text { electromagnet control winding }\end{array}$ & 2 \\
\hline 5 & Contact system resistance measurement & 4 \\
\hline 6 & Operating test & 4 \\
\hline 7 & Thermal imaging control of contact joint & 4 \\
\hline
\end{tabular}

\section{Conclusion}

This paper discusses the possibility of applying fuzzy neural networks for equipment technical state assessment at electrical substations. Such equipment assessment technology can become the first step in intelligent control systems development.

\section{References}

[1] Ram S., Chandel A.K., Singh G., Mondal M., UV Spectrophotometer Based AI Techniques for Remnant Life Estimation of Power Transformers, IOSR Journal of Electrical and Electronics Engineering (IOSR-JEEE), vol. 3: issue 3, pp. 46-55, 2012.

[2] Birger I. A., Technical Diagnostics, Mechanical engineering: Moscow, pp. 45-48, 1978.

[3] Khalyasmaa, A. I., Dmitriev, S. A., Eroshenko S. A., Membership functions for the formation of the electrical equipment state estimation for power stations and substations, Advanced Materials Research, vol. 805-806, pp. 663-666, 2013.

[4] Wu Y., Zhang B., Lu J., Du K.-L., Fuzzy Logic and Neuro-fuzzy Systems: A Systematic, International Journal of Artificial Intelligence and Expert Systems (IJAE), vol. 2: issue 2, pp. 47-80, 2011.

[5] Amina M., Kodogiannis M. S., Petrounias I., Tomtsis D., A hybrid intelligent approach for the prediction of electricity consumption, Electrical Power and Energy Systems, vol. 43, pp. 99-108, 2012.

[6] Gelman A., Carlin J. B., Stern H. S., Rubin D. B., Bayesian data analysis, 2nd ed. Boca Raton: Chapman Hall and CRC Press; 2003. 